\title{
Community Science: An Approach for Rural Development
}

\author{
Komal Thakur ${ }^{1 *}$, Shipra Karn ${ }^{2}$, Nishant Prakash ${ }^{3}$, Parul Barteja ${ }^{4}$ and Nimita Kandwal ${ }^{5}$ \\ ${ }^{1}$ Punjab Agriculture University, Ludhiana, Punjab, India \\ ${ }^{2}$ Darwin School of Business, Guwahati, Assam, India \\ ${ }^{3}$ Krishi Vigyan Kendra, Arwal, Bihar, India \\ ${ }^{4}$ National Institute of Technology, Kurukshetra, Haryana, India \\ ${ }^{5}$ G.B. Pant University of Agriculture and Technology, Pantnagar, Uttarakhand, India \\ *Corresponding author
}

\section{A B S T R A C T}

\begin{tabular}{|l|}
\hline Ke y w o r d s \\
Community \\
science, \\
Community science \\
centre, Science and \\
Practice
\end{tabular}

\section{Introduction}

Community science is an institution that deals with the application of science in socioeconomic development of rural area. It is defined as "A multidisciplinary field that attempts to strengthen community functioning by investigating how to improve the quality of common approaches (prevention, treatment, education, health promotion) implemented in real world settings (Chinman et al., 2004). According to some researcher, community psychology is more specific to psychology of
Community science is a multidisciplinary approach to disseminate scientific knowledge among rural people. It involves collective approach of scientist, government, district and regional working personnel. A gap exists between science and its practice in rural areas. Several factors contribute to this gap i.e. inadequate skill, poor financial support, inadequate availability of literature, poor adaptability in local area. To overcome these issues, community science conduct different training, seminar, conferences, nukkad natak, video film to spread scientific awareness among rural people. It enhances scientific knowledge to rural people which in turn change the socio-economic condition of rural area. 
Goatry, cottage industry, rural craft etc.) then satisfactory result can be expected which uplift rural socio-economic status. Usually people working in rural areas lack essential scientific knowledge and information of local issue. As community science is a multidisciplinary approach which involves scientist, experts, central/state government, district and block or regional level community centres (Figure 1). It aims to improve the quality of existing approach implemented in prevailing scenario (Wandersman, 2003). Community science is the best approach to find out the gap as it deals with the developing and evaluating the models of community system in rural area.

Factors responsible for the gap between science and practice in rural area

Lack adequate skill and knowledge: for implementing high level scientific programme, good amount of knowledge and skill is required. For this we need

Assessment of need

Identifying goals and objectives

Development of appropriate program that fits in local area with available resources.

Planning

Implementation

Evaluation of the program.

Differences between researcher and pracititioner knowledge. It occurs due to

Lack of proper liasoning between different concerning agencies system.

Reluctance of community to adopt different evidence based strategies and programs.
Lack of adequate resources: Poor financial support and inadequate availability of scientific literature are major constraints in implementation of scientific knowledge in rural area.

Poor adaption of community science program in existing rural condition. It hinders the dissemination of program.

\section{Objective of Community science study in rural system}

To attract rural people towards science

Inculcating scientific temperament among rural men, women and children

To incorporate scientific activities in the routine life of rural people

To support rural people and students in science and science education

Describe the significance of science in different stages of life among rural people

Illustrate the role of scientific contribution in social development

To spread awareness about the harmful and non-scientific chores of society, superstitions, harmful coustoms and rituals. In addition to spreading awareness, community science also play a role in uprooting these harmful and non-scientific belief among rural people

Describe how scientific attitude/knowledge play a key role in socio-economic development

\section{Function and duties of community science Centres}

In India, different states have established their community science centres. These states are 
Gujarat, Chhattisgarh, Madhya Pradesh etc. These centres operates at district and regional level.

These centres disseminate scientific knowledge to researchers to rural people. The role of community science centres at district and regional levels are as follows:

\section{Regional level community science centres}

To execute all the activities suggested by the district level community science centre in local area

Development of scientific activity module according to the local situation and implementing it at both the local and district level
To organise training, Krishak gosthi, nukkad natak, lectures at both the local and district level to train rural people and extension personnel working in rural area about science

Keep extension personnel of rural area and other rural people and farmers about scientific activities of other states

Updating with the scientific activities of district centres at regular interval

Coordinating with district centres and organising scientific activities in those areas where community science centre does not exist or no any personnel is present

Publication of scientific literature for rural people in local language

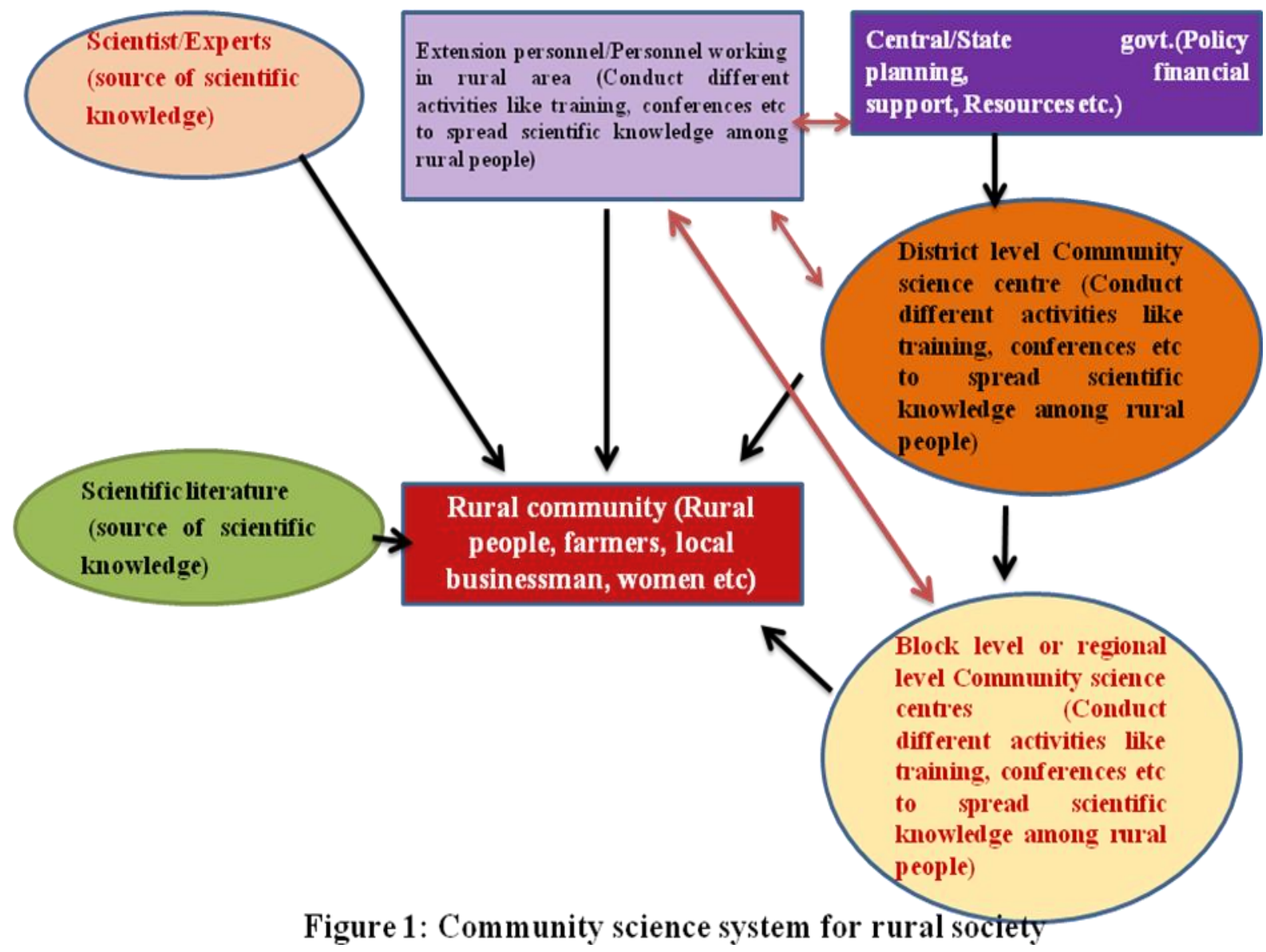




\section{District level community science centres}

Organise scientific activities in different blocks, Panchayat of district as per the varied age and gender of rural people

To constitute science hubs involving farmers, rural businessmen and people of other class from rural area

To aware people, organise scientific lectures, training, drama, street plays regarding nonscientific activities prevailing in the district

To provide scientific guidance to rural people about the natural events like earth quake, eclipse, cyclone etc

To organise program like quiz, science exhibition, science lectures in science hubs of farmers

To organise program about scientific cultivation of crops, soil conservation, water harvesting, organic farming etc among farmers

To spread awareness about healthcare, food and nutrition, diseases etc.

Development of entreneurship

Special training program for tribal community.

Use of video van to spread scientific awareness.

All the above mentioned activities should be done in collaboration with the district centre.

Methodology adopted by community science to for capacity building of rural people are as follow

Review of research and literature
Change in system and community

Survey, focus groups and interviews of stakeholders

Appropriate information system design

Case studies

Quantitative and Qualitative analysis

Learning sessions for interpretation and sharing of informations

Group discussion

Strategy planning session

Rural communities face significant challenges in their farming, health and other issues. Community science approach involves scientific intervention which involves Government, scientist, researchers, district and regional working personnel. Community science approach conduct various training, conferences and other approach to incorporate scientific knowledge in their rural farming and other life style. It improves socioeconomic condition of farmers and rural people.

\section{References}

Chinman, M., Early, D., Ebener, P., Hunter, S., Imm, P., Jenkins, P., Sheldon, J., and Wandersman, A. 2004. Getting To Outcomes: A community-based participatory approach to preventive interventions. Journal of Interprofessional Care, 18, 441-443.

Miller R.L. and Shinn M. 2005. Learning form communities: Overcoming difficulties in dissemination of prevention and promotion efforts. American Journal of Community Psychology; 35 (34):169-183. 
Tebes J.K. 2005. Community science, Wandersman, A. and Florin, P. 2003. philosophy of science, and the practice of research. American Journal of Community Psychology; 35 (34): 213230. Community interventions and effective prevention. American Psychologist, 58, $441-448$

\section{How to cite this article:}

Komal Thakur, Shipra Karn, Nishant Prakash, Parul Barteja and Nimita Kandwal. 2019. Community Science: An Approach for Rural Development. Int.J.Curr.Microbiol.App.Sci. 8(08): 6-10. doi: https://doi.org/10.20546/ijcmas.2019.808.002 